\title{
Temperature-dependent effects of PFOS on risk recognition and fast-start performance in juvenile Spinibarbus sinensis
}

\author{
Ji-Gang Xia, Yi-Jie Ma, Wu-Mei Guo, Li Huang, Shi-Jian Fu* \\ Laboratory of Evolutionary Physiology and Behavior, Chongqing Key Laboratory of Animal Biology, \\ College of Life Sciences, Chongqing Normal University, 401331 Chongqing, PR China
}

\begin{abstract}
Perfluorooctane sulfonate (PFOS) is a synthetic chemical substance that has become a ubiquitous environmental contaminant. It has been used in both industrial and consumer applications for over $50 \mathrm{yr}$, resulting in high levels of contamination worldwide. The potential ecotoxicity of PFOS has recently become a focus of interest and concern. The aim of this study was to investigate the impact of PFOS on risk recognition and escape performance of juvenile qingbo Spinibarbus sinensis. Fish were exposed to a range of PFOS concentrations $(0,0.32,0.8,2$ and $\left.5 \mathrm{mg} \mathrm{l}^{-1}\right)$ at different temperatures $\left(18\right.$ and $\left.28^{\circ} \mathrm{C}\right)$ for $4 \mathrm{wk}$, at which point their antipredator behavior and fast-start swimming performance were assessed. We found that PFOS exposure caused qingbo to increase the time they spent in the 'risky area' (the area of the experimental aquarium closest to the predator tank) and reduce their average distance from the predator, as well as resulting in a noticeable increase in latency time and a significant decline in maximum linear velocity, maximum linear acceleration and escape distance. Many of these effects were more pronounced at the higher temperature. Our results indicate that exposure to PFOS could have deleterious effects on survival-related behavior in fish.
\end{abstract}

KEY WORDS: Risk recognition · Fast-start · Ecotoxicology $\cdot$ Perfluorooctane sulfonate $\cdot$ PFOS Temperature

\section{INTRODUCTION}

Perfluorinated compounds (PFCs) are a class of synthetic chemical compounds that have been used in a vast array of industrial and commercial applications for the past $50 \mathrm{yr}$, including surface protection (e.g. water-, oil-, and soil-resistant coatings for textiles, carpets, and upholstery), food-package treatments, fire retardants, lubricants and insecticides (Giesy \& Kannan 2001, Fuentes et al. 2007, Pereiro et al. 2014). The high-energy carbon-fluorine bonds are among the strongest in organic chemistry, and this stability make these compounds resistant to photolysis, hydrolysis and defluorination, and therefore practically nonbiodegradable (Key et al.

\footnotetext{
${ }^{*}$ Corresponding author: shijianfu9@hotmail.com
}

1997, Beach et al. 2006). As one of the most commonly detected perfluorinated alkylated substances in aquatic ecosystems, perfluorooctane sulfonate (PFOS) has become the target of public concern and has been declared a persistent organic pollutant (Stockholm Convention 2009) due to its potential toxicity to animals, persistence in the environment and global occurrence (Ferrey et al. 2012, Hagenaars et al. 2014).

The ecological effects of PFOS on the fitness of aquatic organisms have been a subject of great interest. Most toxicological tests concerning PFOS in fish have focused on metabolic, reproductive and developmental aspects (Hagenaars et al. 2008, Han \& Fang 2010, Dorts et al. 2011). However, there is limited but

() The authors 2015. Open Access under Creative Commons by Attribution Licence. Use, distribution and reproduction are unrestricted. Authors and original publication must be credited. 
growing evidence linking PFOS exposure to the toxic contamination of the central nervous system (Austin et al. 2003, Johansson et al. 2009, Chen et al. 2014). As reported by Johansson et al. (2009), PFOS exposure can affect processes linked to neurodegeneration, thereby affecting cognitive function. In this context, it is plausible to suppose that certain behaviors could be adversely affected by PFOS. However, to date few studies have assessed the effects of PFOS on fish behavior (e.g. antipredator behavior). In a previous publication, we reported that short-term PFOS exposure could cause behavioral defects in fish (manifested as reduced spontaneous activity), although no significant changes in swimming capabilities were observed (Xia et al. 2013). Are the fitness-related behavioral traits of fish susceptible to chronic PFOS exposure? One goal of this study was to determine whether PFOS exposure has an effect on risk recognition and escape performance. Importantly, many fish in natural water bodies are subjected to large seasonal changes in temperature. An altered thermal environment can also change the effects of a toxicant (Langberg 2014); thus, another goal of this study was to determine whether the effects of PFOS on risk recognition and fast-start performance were temperature-dependent.

In general, prey species can demonstrate an antipredator response upon encountering a predator. The ability of a prey fish to recognize and respond appropriately to predation risk decreases its probability of being captured (Kiesecker et al. 2002). Conversely, the impairment of antipredator traits could directly reduce prey survival when encountering predators (Janssens \& Stoks 2012). Given the high impact and frequency at which predation events occur in ecosystems, studies focusing on how a given pollutant affects key antipredator traits in prey species are important to increase our understanding of the ecotoxicological effects of pollutants in nature (Trekels et al. 2012). Following exposure to a perceived risk, fish usually resort to escape behavior using a 'fast-start' (Domenici et al. 2007). Fast-start swimming, which lasts for less than approximately $1 \mathrm{~s}$, is crucial for most fish in predator-prey interactions (Domenici \& Blake 1997, Tudorache et al. 2008). Ecologically, decreased antipredator response or impairment of the fast-start performance in a polluted environment (such as that caused by PFOS contamination) may render animals more vulnerable to predation. Therefore, the extent to which fish can maintain their risk recognition and escape performance would be closely related to their fitness.

\section{MATERIALS AND METHODS}

\section{Animals and test chemicals}

The qingbo Spinibarbus sinensis is a fish endemic to China that is highly sensitive to changes in environmental conditions in its habitat and is mainly distributed in the upper reaches of the Yangtze River (Pang et al. 2011). Juvenile fish of uniform size $(2.69 \pm 0.04 \mathrm{~g}, 5.39 \pm 0.03 \mathrm{~cm}, \mathrm{n}=200)$ were obtained from local farmers in Chongqing Municipality, China. Prior to the experiment, the fish were reared in a 1201 recirculating water tank system for $2 \mathrm{wk}$. The rearing water was dechlorinated and filtered through activated carbon. Water temperature was maintained at $22 \pm 1{ }^{\circ} \mathrm{C}$, water oxygen content was kept above $7 \mathrm{mg} \mathrm{l}^{-1}, \mathrm{pH}$ ranged from 6.8 to 7.5 , ammonia-N ranged from 0.005 to $0.02 \mathrm{mg} \mathrm{l}^{-1}$, and the rearing system was maintained under a $15 \mathrm{~h}$ light: $9 \mathrm{~h}$ dark cycle. The fish were fed to satiation daily with commercial Tubifex spp. After the acclimation period, healthy fish of similar sizes were selected for the study.

We used juvenile southern catfish Silurus meridionalis $(95.0$ to $97.4 \mathrm{~g}, 19.6$ to $20.2 \mathrm{~cm}$ ) to provide the predator stressor in this study. This species was chosen mainly because (1) it is a predator that qingbo frequently encounter in nature and (2) it is a typical ambush (i.e. sit-and-wait) predator that usually remains stationary for long times (Fu et al. 2009). The southern catfish were obtained from local fisheries and acclimated in a rearing system for $2 \mathrm{wk}$. The conditions of the rearing system were similar to those of qingbo described above, except that the water temperature was $24 \pm 1^{\circ} \mathrm{C}$ and the fish were fed with juvenile qingbo.

Heptadecafluorooctanesulfonic acid potassium salt (PFOS; purity > 99\%) was purchased from Tokyo Kasei Kogyo; other chemicals were obtained from Sigma-Aldrich. PFOS was initially dissolved in dimethyl sulfoxide (DMSO), and the stock solution $\left(0.5 \mathrm{~g} \mathrm{ml}^{-1}\right)$ was stored at $4^{\circ} \mathrm{C}$ until preparation of the final exposure solutions in water.

\section{Experimental design and protocol}

We used a semi-static exposure experiment apparatus for waterborne PFOS exposure. The apparatus consisted of 10 glass aquaria (length $\times$ width $\times$ height: $42 \times 22 \times 42 \mathrm{~cm}$ ), each with a capacity of approximately 221 .

Prior to exposure, the juvenile qingbo were randomly selected and divided into 10 groups $(\mathrm{n}=16$ for 
each group) and were gently transferred to the aquariums. Fish were maintained at conditions similar to those described above for $1 \mathrm{wk}$ to eliminate stress effects. For each group, the same amount of food (approximately $10 \%$ of body weight) was provided daily during this period and during subsequent processing. After that, the water temperature was increased or decreased by $1{ }^{\circ} \mathrm{C} \mathrm{d}^{-1}$ until it reached a prescribed temperature $\left(18\right.$ or $\left.28^{\circ} \mathrm{C}\right)$. The selected temperatures were chosen based on the habitat/season temperature. For qingbo, the habitat temperature is approximately $18^{\circ} \mathrm{C}$ in spring and autumn and approximately $28^{\circ} \mathrm{C}$ in summer. We hypothesized that an increase in the seasonal temperature would enhance the ecotoxicity of PFOS to the fish.

Once the water temperature reached the prescribed values, the toxicants were administered. Fish were exposed to a range of PFOS concentrations $(0$, $0.32,0.8,2$ and $5 \mathrm{mg} \mathrm{l}^{-1}$ ) under the 2 different temperatures $\left(18\right.$ and $\left.28^{\circ} \mathrm{C}\right)$ for $4 \mathrm{wks}$. The concentration of DMSO in the water did not exceed $0.001 \%(\mathrm{v} / \mathrm{v})$. During the experimental period, $50 \%$ of the exposure solution was renewed daily (Shi et al. 2009). Water disposal from the aquaria was filtered through activated carbon before being delivered into the municipal sewage system. After termination of PFOS exposure, feeding was withheld for $48 \mathrm{~h}$ and the antipredator behavior and fast-start performance of the fish were examined successively.

The experimental protocols used in this study were in strict accordance with current guidelines for the care of laboratory animals and ethical standards permissible for investigations in conscious animals (Zimmermann 1983). At the end of the experiment, fish were anesthetized in tricaine methanesulfonate (MS-222, $50 \mathrm{mgl}^{-1}$ ).

\section{Antipredator behavior}

Tests to the assess antipredator behavior of the fish were carried out in an interference-free behavioral observation chamber. The system consisted of 3 rectangular glass aquariums, a video camera and a computer (Fig. 1). The testing tank (length $\times$ width $\times$ height: $72 \times 12 \times 42 \mathrm{~cm}$ ) was placed in the middle position. A second tank $(20 \times 12 \times 42 \mathrm{~cm})$ containing a predator (southern catfish) was closely placed on one side of the testing tank, and an identical empty fish tank (containing only water, used as the control tank) was placed on the other side. The depth of water in all aquaria was $16 \mathrm{~cm}$, and the dissolved oxygen level was maintained above $7 \mathrm{mg} \mathrm{l}^{-1}$. The water temperature was maintained at 18 or $28^{\circ} \mathrm{C}$ in the testing tank, which was consistent with the temperature during the exposure period. For the predator, the water temperature was maintained at $24^{\circ} \mathrm{C}$, which is the value used for acclimation. A video camera (Sony) was installed $1.5 \mathrm{~m}$ in front of the testing tank and was operated by remote control.

Prior to the start of the test, the experimental fish were fasted for $48 \mathrm{~h}$ and the predators were fed to satiation. The head of the predator was positioned close to the testing tank. The behavioral assays were conducted after the light had been on for at least $1 \mathrm{~h}$. Individual fish were carefully moved into the testing arena and the operator left the room immediately. The testing tank was initially obscured by opaque Plexiglas barriers $(12 \times 16 \mathrm{~cm})$ at the ends of the chamber. Fish were allowed to habituate to the novel environment for $15 \mathrm{~min}$. After that, the barriers were carefully removed at the same time. Thus, the antipredator behavior of the test fish would be provoked by the appearance of the predator. The behaviors of the fish were then recorded on video for $5 \mathrm{~min}$. The predators were relatively stationary (the centroid speed was not greater than $1.0 \mathrm{~cm} \mathrm{~s}^{-1}$ ) during the experimental trials and made no attempts to attack the prey or to escape their containers. If the predator did not remain calm during the measurement, data from that trial were discarded. Fish were tested in a randomized order across all treatment groups. The water in the testing tank was replaced with each subsequent test fish.

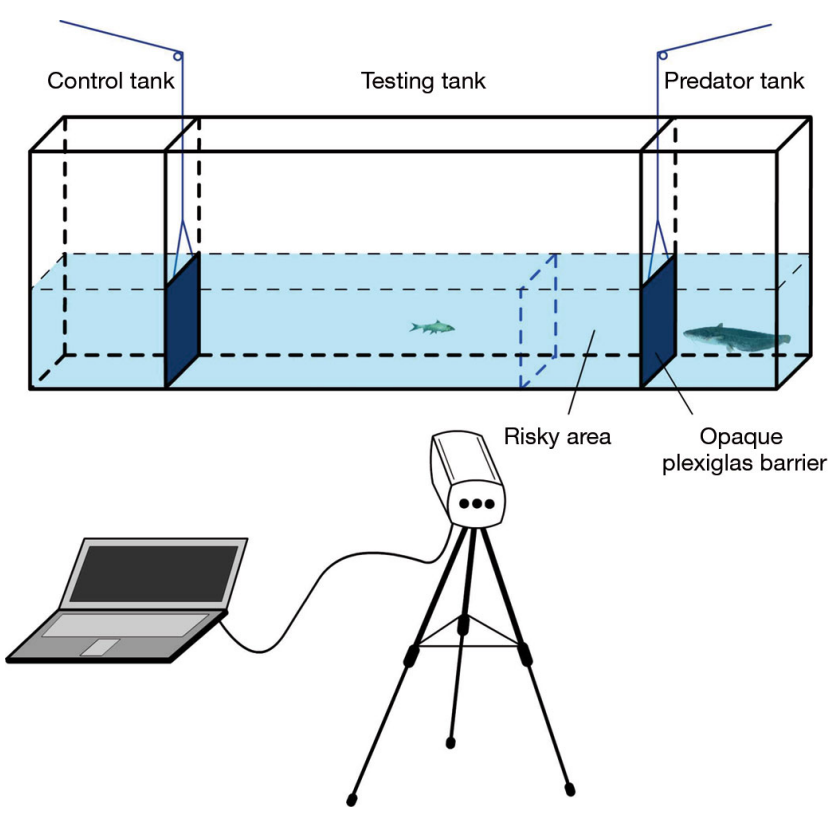

Fig. 1. Experimental chamber used to assess antipredator behavior of juvenile qingbo Spinibarbus sinensis 
EthoVision XT 9.0 video tracking software (Noldus) was used to assay and quantify the antipredator behavior of the fish. The program compared each incoming image sample with the original background. Image samples were taken at a rate of 30 frames $\mathrm{s}^{-1}$. For each fish, the percentage of time spent in the 'risky area', the use of the risky area (times), and the average distance to the predator were calculated. The risky area was defined as the quarter of the length of the aquarium closest to the predator tank (Fig. 1) based on results of pre-experiments (data not shown). Quantification of all of the distance measures was achieved after calibration of the EthoVision software by inputting the actual dimensions of the testing tank.

\section{Fast-start performance}

The fast-start swimming performance of the fish was assessed with a device developed by our laboratory (Xia et al. 2013), which consisted of a quadrate testing tank $(40 \times 40 \times 15 \mathrm{~cm})$, a direct current, an electrical pulse generator, a high-speed camera (BASLER A504K) and a computer. A reference grid of $1 \mathrm{~cm}$ squares and an LED matrix light source were positioned at the bottom of the testing tank.

The fish were dorsally marked at the center of the mass (CM) position with titanium oxide before the experiment. Individual fish were gently placed in the testing tank and were allowed to habituate to the novel environment for $30 \mathrm{~min}$. The depth of the water in the tank was $8 \mathrm{~cm}$, the dissolved oxygen level was maintained above $7 \mathrm{mg} \mathrm{l}^{-1}$, and the temperature was maintained at the values used for the exposure treatment of the fish $\left(18\right.$ or $\left.28^{\circ} \mathrm{C}\right)$. The water in the tank was replaced with each fish to rid the tank of the potential impact of the previously tested fish.

Fast-start responses were elicited by an electrical pulse $\left(0.75 \mathrm{~V} \mathrm{~cm}^{-1} ; 50 \mathrm{~ms}\right)$, which was administered when the fish was stationary and maintaining a position at the center of the filming zone (Xia et al. 2013, $\mathrm{Fu}$ 2015). A high-speed camera (500 frames $\mathrm{s}^{-1}$ ) was used to record the escape trajectory of the fish. The resulting images were initially processed using nEOiMAGING and ACDSee 12 software and subsequently digitized using TpsUnil and TpsDig software (http://life.bio.sunysb.edu/morph/) to examine the displacement of the $\mathrm{CM}$ of the fish during the escape response. The following parameters were calculated based on the locomotion track of CM: latency time $\left(T_{\text {latency }}\right)$, maximum linear velocity $\left(V_{\max }\right)$, maximum linear acceleration $\left(A_{\max }\right)$, and distance $\left(D_{120 \mathrm{~ms}}\right)$ cov- ered by each fish within $120 \mathrm{~ms}$ after the stimulus onset, considering both response latency and cumulative distance. Here, the parameter $D_{120 \mathrm{~ms}}$ was determined according to the results of pre-experiments, in which we determined that the main escape process of the fish ended at approximately $120 \mathrm{~ms}$.

\section{Statistical analyses}

Statistical analysis was performed using the software program SPSS v.16.0. The data were first examined for normality and homogeneity of variance. The effects of PFOS and temperature on the measured variables were detected using a 2-way ANOVA. The ANOVA was followed by a Tukey's test (PFOS effect) or $t$-test (temperature effect), if necessary, to determine statistical significance among different PFOS treatment groups. Additionally, if the data did not show homogeneity of variances, a Kruskal-Wallis test followed by a Dunnett's T3 test was conducted. All values are presented as means \pm SE. Results were considered significant at $\mathrm{p}<0.05$.

\section{RESULTS}

\section{Antipredator behavior}

Both PFOS treatment $\left(F_{4,110}=6.33, \mathrm{p}<0.001\right)$ and temperature $\left(F_{1,110}=12.9, \mathrm{p}<0.001\right)$ had significant effects on the time individuals spent in the 'risky area,' which increased with increased PFOS concentration (Fig. 2A). The percentage of time that the fish spent in the risky area was significantly affected by PFOS exposure $\left(F_{4,110}=4.78, \mathrm{p}=0.001\right)$ and temperature $\left(F_{1,110}=7.72, \mathrm{p}=0.006\right)$ (Fig. $\left.2 \mathrm{~B}\right)$. The average distance to predator was also significantly affected by PFOS treatment $\left(F_{4,110}=7.62, \mathrm{p}<0.001\right)$ and temperature $\left(F_{1,110}=4.09, \mathrm{p}=0.046\right)$ (Fig. $2 \mathrm{C}$ ). In addition, significant differences in the above parameters were observed between 28 and $18^{\circ} \mathrm{C}$ after exposure to $2 \mathrm{mg} \mathrm{l}^{-1}$ PFOS. Both the lowest observed effect concentration (LOEC) and no observed effect concentration (NOEC) of PFOS for the above parameters were lower at $28^{\circ} \mathrm{C}$ than that at $18^{\circ} \mathrm{C}$ (Table 1).

\section{Fast-start performance}

Both PFOS $\left(F_{4,110}=5.34, \mathrm{p}=0.001\right)$ and temperature $\left(F_{1,110}=115.9, \mathrm{p}<0.001\right)$ had significant effects on $T_{\text {latency }}$ (Fig. 3A). $V_{\max }$ was also significantly af- 

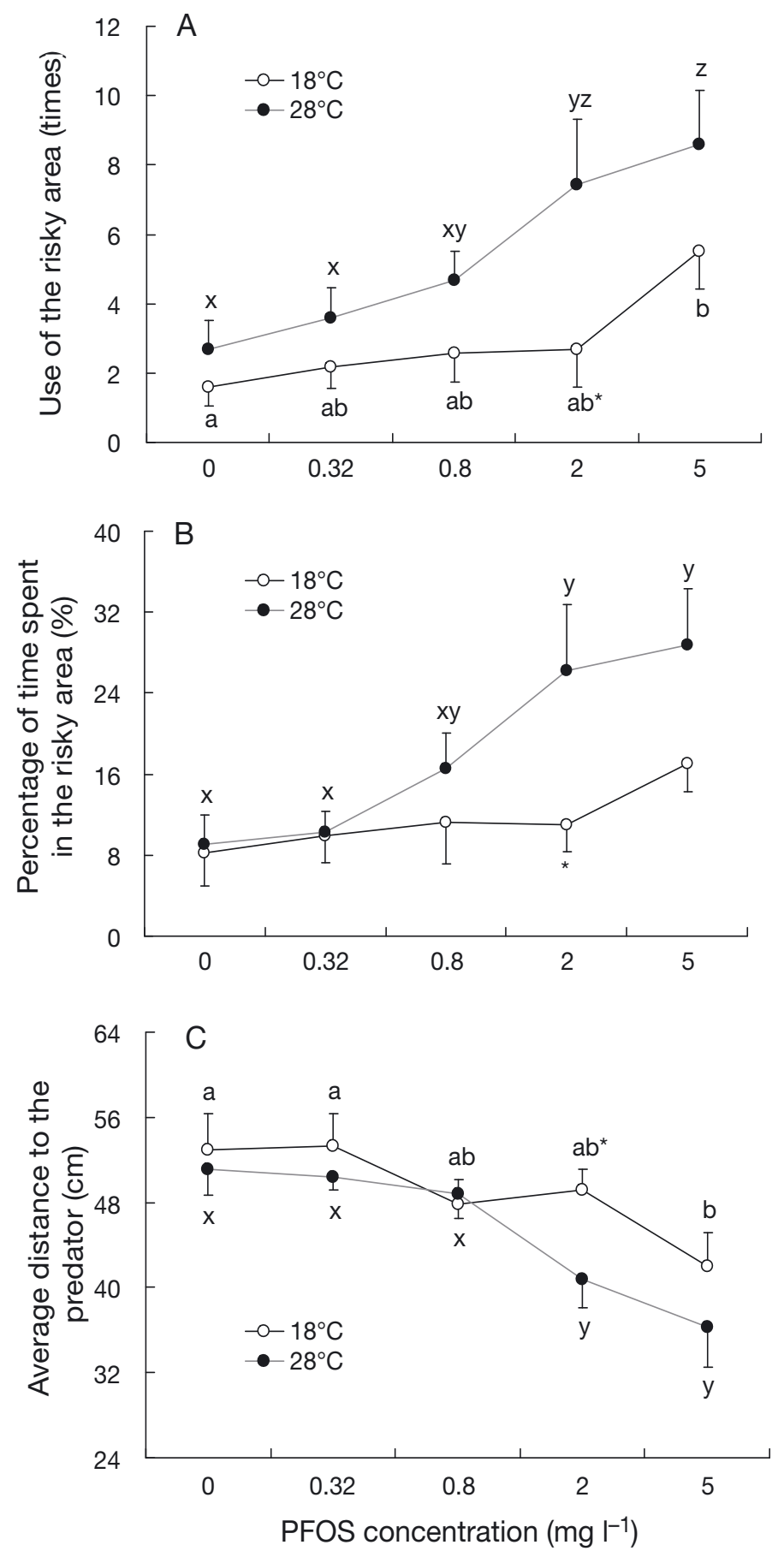

Fig. 2. Effects of perfluorooctane sulfonate (PFOS) on risk recognition by juvenile qingbo Spinibarbus sinensis at different temperatures, showing (A) use of the risky area (cumulative number of times), (B) percentage of time spent in the risky area and $(\mathrm{C})$ average distance to the predator. Data are mean \pm SE. Values in the $18^{\circ} \mathrm{C}$ groups $(n=12)$ without a common lowercase letter $(\mathrm{a}, \mathrm{b})$ are significantly different $(\mathrm{p}<$ $0.05)$; values in the $28^{\circ} \mathrm{C}$ groups $(\mathrm{n}=12)$ without a common lowercase letter $(\mathrm{x}, \mathrm{y}, \mathrm{z})$ are significantly different $(\mathrm{p}<0.05)$; *significant difference between the 18 and $28^{\circ} \mathrm{C}$ groups $(\mathrm{p}<0.05)$
Table 1. No observed effect concentration (NOEC) and lowest observed effect concentration (LOEC) values of perfluorooctane sulfonate (PFOS) for the parameters of antipredator behavior and fast-start performance in juvenile qingbo Spinibarbus sinensis at different temperatures. $T_{\text {latency }}$ latency time; $V_{\max }$ : maximum linear velocity; $A_{\text {max }}$ : maximum linear acceleration; $D_{120 \mathrm{~ms}}$ : distance covered by each fish within $120 \mathrm{~ms}$ of stimulus onset

\begin{tabular}{|lcccc|}
\hline & \multicolumn{2}{c}{$\operatorname{NOEC}\left(\mathrm{mg} \mathrm{l}^{-1}\right)$} & \multicolumn{2}{c}{$\mathrm{LOEC}\left(\mathrm{mg} \mathrm{l}^{-1}\right)$} \\
& $18^{\circ} \mathrm{C}$ & $28^{\circ} \mathrm{C}$ & $18^{\circ} \mathrm{C}$ & $28^{\circ} \mathrm{C}$ \\
\hline Antipredator behavior & & & & \\
$\begin{array}{l}\text { Increased use of risky area } \\
\text { Increased \% time spent in }\end{array}$ & 2 & 0.8 & 5 & 2 \\
$\quad$ risky area & - & 0.8 & - & 2 \\
$\begin{array}{l}\text { Decreased avg. distance to } \\
\text { predator }\end{array}$ & 2 & 0.8 & 5 & 2 \\
$\begin{array}{l}\text { Fast-start performance } \\
\text { Increased } T_{\text {latency }}\end{array}$ & 2 & 0.8 & 5 & 2 \\
$\begin{array}{l}\text { Decreased } V_{\max } \\
\text { Decreased } A_{\max }\end{array}$ & 2 & 2 & 5 & 5 \\
Decreased $D_{120 \mathrm{~ms}}$ & 0.32 & 0.32 & 0.8 & 0.8 \\
& 2 & 2 & 5 & 5 \\
\hline
\end{tabular}

fected by PFOS exposure $\left(F_{4,110}=9.67, \mathrm{p}<0.001\right)$ and temperature $\left(F_{1,110}=10.6, \mathrm{p}=0.001\right)$ (Fig. 3B), as was $A_{\text {max }}$ (PFOS treatment: $F_{4,110}=12.3, \mathrm{p}<0.001$; temperature: $F_{1,110}=21.7, \mathrm{p}<0.001 ;$ Fig. $3 \mathrm{C}$ ) and $D_{120} \mathrm{~ms}$ (PFOS treatment: $F_{4,110}=8.27, \mathrm{p}<0.001$; temperature: $F_{1,110}=31.4, \mathrm{p}<0.001$; Fig. 3D). The $V_{\max } A_{\max }$ and $D_{120 \mathrm{~ms}}$ of the fish all decreased with increasing PFOS concentration, whereas the $T_{\text {latency }}$ increased. Both LOEC and NOEC of PFOS for $\mathrm{T}_{\text {latency }}$ were lower at $28^{\circ} \mathrm{C}$ than that at $18^{\circ} \mathrm{C}$ (Table 1 ).

\section{DISCUSSION}

Fish exposed to PFOS showed a decrease in antipredator behavior and fast-start performance, suggesting that PFOS, a common PFC contaminant, may have significant negative effects on the risk recognition and escape behavior in prey species. Furthermore, the high temperature treatment caused enhanced toxicity of PFOS, suggesting that ecological risk assessments in the field should be based, in part, on the results of toxicity tests conducted under given seasonal conditions.

Studies have shown that PFOS exposure can cause neurotoxicity and cognitive behavior defects, such as the recently-described 'hyperactive/impulsive motor phenotype'. As reported by Spulber et al. (2014), zebrafish larvae exposed to $1 \mathrm{mg} \mathrm{l}^{-1}$ PFOS displayed a disorganized pattern of spontaneous activity and persistent hyperactivity. In the current study, we clearly demonstrated that $2 \mathrm{mg} \mathrm{l}^{-1}$ PFOS exposure at 

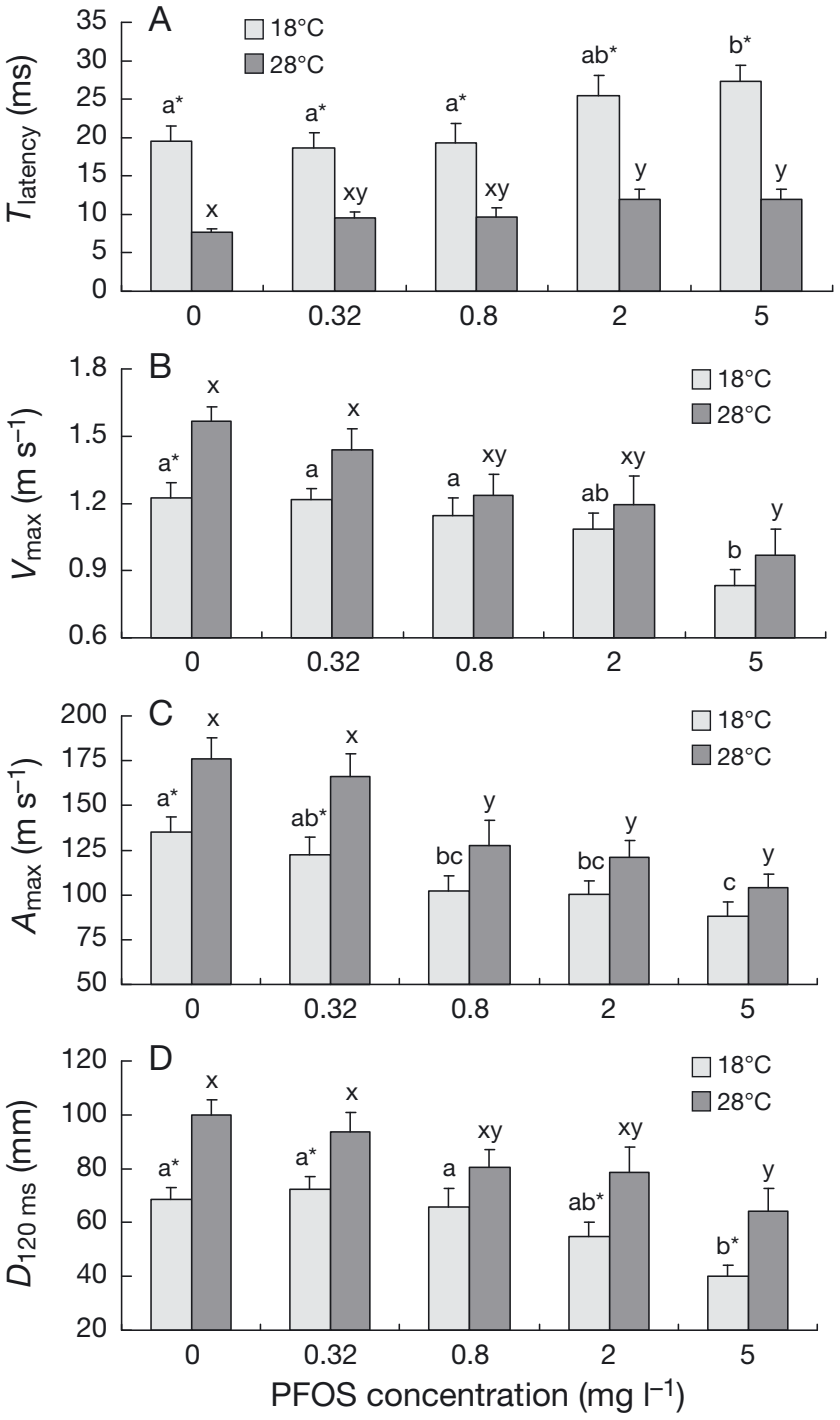

Fig. 3. Effects of perfluorooctane sulfonate (PFOS) on faststart performance of juvenile qingbo Spinibarbus sinensis at different temperatures, showing (A) latency time ( $\left.T_{\text {latency }}\right)$, (B) maximum linear velocity $\left(V_{\max }\right)$, (C) maximum linear acceleration $\left(A_{\max }\right)$ and $(D)$ distance covered within $120 \mathrm{~ms}$ after the stimulus onset $\left(D_{120 \mathrm{~ms}}\right)$. Data are mean \pm SE. Values in $18^{\circ} \mathrm{C}$ groups $(\mathrm{n}=12)$ without a common lowercase letter $(\mathrm{a}, \mathrm{b}, \mathrm{c})$ are significantly different $(\mathrm{p}<0.05)$; values in $28^{\circ} \mathrm{C}$ groups $(\mathrm{n}=12)$ without a common lowercase letter $(\mathrm{x}, \mathrm{y})$ are significantly different $(\mathrm{p}<0.05) ;{ }^{*}$ significant difference between the 18 and $28^{\circ} \mathrm{C}$ groups $(\mathrm{p}<0.05)$

$28^{\circ} \mathrm{C}$ resulted in a reduced antipredator response by the fish, manifested as a higher frequency of use of the risky area, an increased percentage of time that the fish spent in the risky area, and a strong decrease in the average distance to the predator. Potentially, a variety of mechanisms might be responsible for the alterations in antipredator behavior caused by PFOS. Johansson et al. $(2008,2009)$ speculated that PFOS exposure could affect processes linked to neuro- degeneration, thereby affecting cognitive function. Chen et al. (2014) reported that in Caenorhabditis elegans, PFOS induced obvious behavioral defects (e.g. the decline of chemotaxis learning ability) and neurotoxicity via oxidative stress damages. They proposed that the neurotoxicity of PFOS was mediated, at least in part, by an oxygen radical mechanism involving overproduction of reactive oxygen species (ROS) and downregulation of certain key antioxidant enzymes such as glutathione peroxidase (GPX). Additionally, the glucocorticoid hormones cortisol and corticosterone are considered to facilitate components of antipredator behavior in animals because they prepare the body to perform behaviors that address stressors (Barreto et al. 2014). PFOS exposure induced a global inhibition of the hypothalamic-pituitary-adrenal (HPA) axis activity, resulting in decreased corticosterone secretion and release (Pereiro et al. 2014), and ultimately affecting the antipredator response.

Fast-start swimming is typically controlled by the Mauthner cells, a pair of large reticulospinal neurons that receive various sensory inputs and are powered by intracellular stores of adenosine triphosphate (ATP) and creatine phosphate (Reidy et al. 2000, Marras et al. 2011). From an ecological point of view, fast-start swimming is of great importance for both predator avoidance and prey capture. To our knowledge, however, there is little information available on the effects of pollutants on fast-start swimming. Our previous study indicated that fast-start performance in juvenile goldfish Carassius auratus was not affected by short-term (48 h) exposure to PFOS (Xia et al. 2013). However, the present study demonstrated that longer-term (4 wk) exposure to PFOS potently inhibited the fast-start performance of juvenile qingbo (manifested as increased $T_{\text {latency, }}$ and decreased $V_{\max }, A_{\max }$ and $D_{120 \mathrm{~ms}}$ ). This indicated that the effect of PFOS on fast-start performance is probably related to the length of exposure. Given that exposure to PFCs (e.g. perfluorooctanoic acid) can result in an impairment of aerobic ATP production, depletion of liver glycogen stores and altered expression levels of transcripts involved in carbohydrate metabolism (Hagenaars et al. 2013), we postulate that the reduced fast-start performance caused by chronic PFOS exposure was due to the disturbance of the Mauthner system and a constraint in muscle power output. According to Walker et al. (2005), faster fast-starts increase the probability of evading predators. Therefore, the reduced $V_{\max } A_{\max }$ and $D_{120 \mathrm{~ms}}$ in this study indicate that fish exposure to PFOS would be subjected to a higher risk of being captured by a predator. 
Temperature is one of the most important abiotic factors in the habitats of ectothermic animals and has been coined the 'ecological master factor' for fish (Brett 1971). Our results demonstrate that the effects of PFOS on risk recognition and fast-start performance was temperature-dependent, i.e. higher temperatures magnified the toxic effects of PFOS. Of note, PFOS treatment in our experiment resulted in a remarkable decrease in the average distance the qingbo maintained from the predator, which was reduced by 20.5 and $29.0 \%$ after exposure to the highest concentration of PFOS $\left(5 \mathrm{mg} \mathrm{l}^{-1}\right)$ at 18 and $28^{\circ} \mathrm{C}$, respectively. In general, fish exhibit decreased fast-start performance at low temperatures compared to high temperatures (Domenici \& Blake 1997). However, significant differences in $V_{\max }$ and $A_{\max }$ were not observed between 18 and $28^{\circ} \mathrm{C}$ in cases where the PFOS concentration was $>0.32 \mathrm{mg}$ $\mathrm{l}^{-1}$. This was mainly because PFOS had a more profound effect on the experimental fish at the higher temperature. For example, after exposure to $0.8,2$ and $5 \mathrm{mg} \mathrm{l}^{-1}$ PFOS, the values of $V_{\max }$ decreased by $6.5,11.5$ and $31.9 \%$, respectively at $18^{\circ} \mathrm{C}$, in comparison to a decrease of $21.1,23.8$, and $38.1 \%$, respectively at $28^{\circ} \mathrm{C}$. The increased toxicity of PFOS at the higher temperature was probably due to a faster uptake, absorption and bioaccumulation (Del Piero et al. 2012). The observed temperature-dependent PFOS effects on risk recognition and fast-start performance of the fish provide further support to the appeal by Bednarska et al. (2013) to include a range of realistic temperatures in standard ecotoxicity tests. Our study indicates that PFOS as an environmental pollutant could have ecological consequences for wild fish by decreasing risk recognition and escape behaviors.

Acknowledgements. This study was supported by the National Natural Science Foundation of China (NSFC 31300340), the Natural Science Foundation Project of Chongqing (cstc2015jcyjA20016) and Youth Top-notch Talent Cultivation Program of Chongqing Normal University (14CSBJ08).

\section{LITERATURE CITED}

- Austin ME, Kasturi BS, Barber M, Kannan K, MohanKumar PS, MohanKumar SM (2003) Neuroendocrine effects of perfluorooctane sulfonate in rats. Environ Health Perspect 111:1485-1489

Barreto RE, Barbosa-Junior A, Urbinati EC, Hoffmann A (2014) Cortisol influences the antipredator behavior induced by chemical alarm cues in the frillfin goby. Horm Behav 65:394-400

Beach SA, Newsted JL, Coady K, Giesy JP (2006) Ecotoxicological evaluation of perfluorooctanesulfonate (PFOS).
Rev Environ Contam Toxicol 186:133-174

> Bednarska AJ, Jevtić DM, Laskowski R (2013) More ecological ERA: incorporating natural environmental factors and animal behavior. Integr Environ Assess Manag 9: e39-e46

Brett JR (1971) Energetic responses of salmon to temperature. A study of some thermal relations in the physiology and freshwater ecology of sockeye salmon (OnCorhynchus nerka). Am Zool 11:99-113

Chen N, Li J, Li D, Yang Y, He D (2014) Chronic exposure to perfluorooctane sulfonate induces behavior defects and neurotoxicity through oxidative damages, in vivo and in vitro. PLoS ONE 9:e113453

- Del Piero S, Masiero L, Casellato S (2012) Influence of temperature on fluoride toxicity and bioaccumulation in the nonindigenous freshwater mollusk Dreissena polymorpha Pallas, 1769. Environ Toxicol Chem 31:2567-2571

Domenici P, Blake R (1997) The kinematics and performance of fish fast-start swimming. J Exp Biol 200:1165-1178

> Domenici P, Lefrancois C, Shingles A (2007) Hypoxia and the antipredator behaviours of fishes. Philos Trans R Soc Lond B Biol Sci 362:2105-2121

$>$ Dorts J, Kestemont P, Marchand PA, D'Hollander W, Thézenas ML, Raes M, Silvestre F (2011) Ecotoxicoproteomics in gills of the sentinel fish species, Cottus gobio, exposed to perfluorooctane sulfonate (PFOS). Aquat Toxicol 103:1-8

> Ferrey ML, Wilson JT, Adair C, Su C, Fine DD, Liu X, Washington JW (2012) Behavior and fate of PFOA and PFOS in sandy aquifer sediment. Ground Water Monit Rem 32: 63-71

> Fu SJ (2015) Flow and stress acclimation both enhance predator avoidance in a common cyprinid fish. Aquat Biol 24:1-8

> Fu SJ, Zeng LQ, Li XM, Pang X, Cao ZD, Peng JL, Wang YX (2009) The behavioural, digestive and metabolic characteristics of fishes with different foraging strategies. J Exp Biol 212:2296-2302

Fuentes S, Vicens P, Colomina MT, Domingo JL (2007) Behavioral effects in adult mice exposed to perfluorooctane sulfonate (PFOS). Toxicology 242:123-129

> Giesy JP, Kannan K (2001) Global distribution of perfluorooctane sulfonate in wildlife. Environ Sci Technol 35: $1339-1342$

> Hagenaars A, Knapen D, Meyer IJ, van der Ven K, Hoff P, De Coen W (2008) Toxicity evaluation of perfluorooctane sulfonate (PFOS) in the liver of common carp (Cyprinus carpio). Aquat Toxicol 88:155-163

Hagenaars A, Vergauwen L, Benoot D, Laukens K, Knapen D (2013) Mechanistic toxicity study of perfluorooctanoic acid in zebrafish suggests mitochondrial dysfunction to play a key role in PFOA toxicity. Chemosphere 91: 844-856

Hagenaars A, Stinckens E, Vergauwen L, Bervoets L, Knapen D (2014) PFOS affects posterior swim bladder chamber inflation and swimming performance of zebrafish larvae. Aquat Toxicol 157:225-235

> Han J, Fang Z (2010) Estrogenic effects, reproductive impairment and developmental toxicity in ovoviparous swordtail fish (Xiphophorus helleri) exposed to perfluorooctane sulfonate (PFOS). Aquat Toxicol 99:281-290

Janssens L, Stoks R (2012) How does a pesticide pulse increase vulnerability to predation? Combined effects on behavioral antipredator traits and escape swimming. Aquat Toxicol 110-111:91-98 
Johansson N, Fredriksson A, Eriksson P (2008) Neonatal exposure to perfluorooctane sulfonate (PFOS) and perfluorooctanoic acid (PFOA) causes neurobehavioural defects in adult mice. Neurotoxicology 29:160-169

Johansson N, Eriksson P, Viberg H (2009) Neonatal exposure to PFOS and PFOA in mice results in changes in proteins which are important for neuronal growth and synaptogenesis in the developing brain. Toxicol Sci 108: 412-418

Key BD, Howell RD, Criddle CS (1997) Fluorinated organics in the biosphere. Environ Sci Technol 31:2445-2454

Kiesecker JM, Chivers DP, Anderson M, Blaustein AR (2002) Effect of predator diet on life history shifts of red-legged frogs, Rana aurora. J Chem Ecol 28:1007-1015

Langberg HA (2014) Combined effects of perfluorooctane sulfonic acid (PFOS) and dissolved carbon dioxide $\left(\mathrm{CO}_{2}\right)$ on acute steroidogenic responses in the brain of Atlantic cod (Gadus morhua). MSc thesis, Norwegian University of Science and Technology, Trondheim

> Marras S, Killen SS, Claireaux G, Domenici P, McKenzie DJ (2011) Behavioural and kinematic components of the fast-start escape response in fish: individual variation and temporal repeatability. J Exp Biol 214:3102-3110

Pang X, Cao ZD, Fu SJ (2011) The effects of temperature on metabolic interaction between digestion and locomotion in juveniles of three cyprinid fish (Carassius auratus, Cyprinus carpio and Spinibarbus sinensis). Comp Biochem Physiol A Mol Integr Physiol 159:253-260

Pereiro N, Moyano R, Blanco A, Lafuente A (2014) Regulation of corticosterone secretion is modified by PFOS exposure at different levels of the hypothalamic-pituitaryadrenal axis in adult male rats. Toxicol Lett 230: 252-262

Reidy SP, Kerr SR, Nelson JA (2000) Aerobic and anaerobic

Editorial responsibility: Helmut Segner,

Bern, Switzerland swimming performance of individual Atlantic cod. J Exp Biol 203:347-357

Shi X, Liu C, Wu G, Zhou B (2009) Waterborne exposure to PFOS causes disruption of the hypothalamus-pituitarythyroid axis in zebrafish larvae. Chemosphere 77: 1010-1018

Spulber S, Kilian P, Wan Ibrahim WN, Onishchenko N and others (2014) PFOS induces behavioral alterations, including spontaneous hyperactivity that is corrected by dexamfetamine in zebrafish larvae. PLoS ONE 9:e94227

Stockholm Convention (2009) Report of the conference of the parties of the Stockholm Convention on persistent organic pollutants on the work of its fourth meeting. UNEP/POPS/COP.4/38, United Nations Environment Programme, Nairobi

Trekels H, Van de Meutter F, Stoks R (2012) Species-specific patterns of swimming escape performance and cholinesterase activity in a guild of aquatic insects exposed to endosulfan. Environ Pollut 163:127-133

Tudorache C, Blust R, De Boeck G (2008) Social interactions, predation behaviour and fast start performance are affected by ammonia exposure in brown trout (Salmo trutta L.). Aquat Toxicol 90:145-153

Walker JA, Ghalambor CK, Griset OL, McKenney D, Reznick DN (2005) Do faster starts increase the probability of evading predators? Funct Ecol 19:808-815

> Xia JG, Fu SJ, Cao ZD, Peng JL, Peng J, Dai TT, Cheng LL (2013) Ecotoxicological effects of waterborne PFOS exposure on swimming performance and energy expenditure in juvenile goldfish (Carassius auratus). J Environ Sci (China) 25:1672-1679

Zimmermann M (1983) Ethical guidelines for investigations of experimental pain in conscious animals. Pain 16: $109-110$

Submitted: June 1, 2015; Accepted: September 22, 2015 Proofs received from author(s): October 23, 2015 